\title{
Theoretical and experimental studies of battery charging complexes
}

\author{
Oleh Zimin ${ }^{1}$, Volodymyr Pryvalov ${ }^{2, *}$, Viktoriia Usatenko $^{2}$, and Tetiana Demchenko ${ }^{2}$ \\ ${ }^{1}$ National Accumulator Corporation «ISTA», 49000, Dnipro, Kursantska Str., 30, Ukraine \\ ${ }^{2}$ Institute of Geotechnical Mechanics named by N. Poljakov of National Academy of Sciences of \\ Ukraine, 49005, Dnipro, Simferopolska Str., 2a, Ukraine
}

\begin{abstract}
The possibility of creating highly efficient and safe energy complexes consisting of a rechargeable battery and a charger for operation in mine electric locomotives is being investigated. The analysis of the existing technical level of tools and ways to create energy-saving charging systems were made. The following methods have been prioritized: the use of spreading electrode plates with double separation in conjunction with the compression of the electrode unit; ensuring the recombination of the gas inside the battery on the oxygen cycle. The principles of modeling and algorithms for calculating the basic parameters of battery charging complexes have been developed. The most optimal parameters and conditions of the charging mode, ensuring energy efficiency and fire and explosion safety, are determined. To implement the charging mode, a reliable, safe and energy-saving charger has been proposed, the effectiveness of which is ensured by the following features: minimization of power electronics nodes; the use of a restrictive regulating resistor; natural air cooling.
\end{abstract}

\section{Introduction}

The analysis of the state of the methods and the assessment of the technical level of the means of creating energy-saving charging complexes shows that the reliability and durability of modern acid batteries depend on optimally selected charge modes, which requires an individual selection of chargers for a specific battery size. A properly selected charger improves battery performance, especially when using new battery designs with immobilized electrolyte and oxygen cycle recombination in the long term, that is, with a significant decrease in gassing during their systematic charges. Thus, chargers should be a reliable and relatively simple engineering device with optimal charge management instead of a complex engineering structure using a microprocessor control system and an unreasonable current stability using complex industrial electronics, which objectively reduce the operational reliability of batteries. In addition, it should be borne in mind that existing chargers in the event of their failure, as a rule, require complex and costly repairs.

Currently, the mine electric locomotive modernization program provides for the transfer

\footnotetext{
*Corresponding author: dyakun@ukr.net
} 
of electric locomotives to the power supply from acid traction batteries instead of supplying them to the electric locomotive with alkaline batteries.

The aim of the work is the scientific substantiation of the creation of highly efficient, optimally operating, safe complexes "Battery - Charger", which is an urgent task in the field of energy. The main tasks arising in connection with the goal are the following: analysis of the state of the methods and assessment of the technical level of the means of creating energy-saving charging complexes; development of physical models and algorithms for calculating the basic parameters of battery charging complexes; determination of rational parameters of these complexes; conducting experimental research.

This article is based on previous scientific developments in the form of patents and publications in scientific specialized journals related to the problems of gas formation in lead-acid batteries $[1,2]$, as well as the possibility of creating a low-maintenance lead-acid battery with a low level of gassing during its work [3, 4]. These developments provide the ability to create a standard range of charging devices in an explosion-proof design (CD-RP) destined for automatic charging of acid batteries and their operation on electric locomotives that can work in charging cells (garages) with separate ventilation surfaces and in mines hazardous to coal dust, gas (methane) and / or its sudden emissions.

\section{Methods}

As it is known [5], traction lead-acid $\left(\mathrm{Pb} / \mathrm{PbO}_{2}\right)$ batteries have an advantage in terms of energy characteristics compared to alkaline ones (in industry they are nickel-iron, cadmium-iron). For example, a lead-acid mine battery series 72BAT-640 (battery acid traction) for an electric locomotive (144 V, $640 \mathrm{~A} \cdot \mathrm{h}$ when discharging with a current of 5 hours traction mode $128 \mathrm{~A}$ ) develops a power of $18 \mathrm{~kW}$ and gives off energy of $92 \mathrm{~kW} \cdot \mathrm{h}$. With the same power $(18 \mathrm{~kW})$, an alkaline nickel-cadmium battery $(\mathrm{Cd} / \mathrm{NiOOH})$ is capable of delivering energy $25 \%$ less, namely $69 \mathrm{~kW}$, and with a higher discharge current. Similarly, at $5 \mathrm{~kW} / \mathrm{m}^{3}$, an acid battery produces $120 \mathrm{~kW} / \mathrm{m}^{3}$ versus $90 \mathrm{kWh} / \mathrm{m}^{3}$ alkaline equivalent $\left(\mathrm{Pb} / \mathrm{PbO}_{2}\right.$ acid battery versus $\mathrm{Cd} / \mathrm{NiOOH}$ alkaline). According to specific characteristics per unit mass $(\mathrm{W} / \mathrm{kg}$ versus $\mathrm{W} \cdot \mathrm{h} / \mathrm{kg}$ ), an acid $\mathrm{Pb} / \mathrm{PbO}_{2}$ battery has an advantage over an alkaline $\mathrm{Cd} / \mathrm{NiOOH}$ with discharge currents (0.05-0.07) $C_{\mathrm{N}} \mathrm{A}\left(C_{\mathrm{N}}\right.$ - nominal capacity $)$. Accordingly, it is clear that alkaline traction batteries are inferior acid in reserve energy per unit volume.

An important factor is the cost of the battery. It is known that the service life of alkaline batteries is more than 2 times longer than the service life of lead-acid batteries. Meanwhile, if we take into account that the cost of alkaline traction batteries is 3-4 times higher than the cost of traction lead batteries, then the advantage will be on the side of lead batteries because instead of one alkaline battery, you can buy 3-4 lead batteries (instead of 4000 cycles, you will get much more - from 5600 to 8000 cycles).

The formation of explosive gases when charging lead batteries can be significantly suppressed by recombination [6]. The idea of recombination was formulated and patented by the famous American inventor, entrepreneur and industrialist Edison. But this idea could not be realized due to the lack of appropriate materials, alloys and technologies. Thanks to technical progress, a sealed electrochemical energy source (battery of recombination type) can be developed, built and applied at an industrial serial level.

The main element of the battery charging complex for mine electric locomotives is the traction battery, which is complemented by a charging device as part of the complex. The choice of rational modes of operation of the latter is dictated by the properties of the battery, preferably made on the basis of a lead-acid battery.

To create highly efficient and safe charging systems, two scientific and technical tasks must be solved:

- development of a mechanically more durable energy-saving traction lead-acid battery 
for special purposes (relatively reliable operation in ultra-deep mine conditions) with virtually no self-discharge;

- development of a prototype of a powerful charger, which operates in an optimal automatic mode, for mine battery electric locomotives.

Analyzing the state of creation of modern complexes in the "Charger - traction battery" structure, it should be noted that the battery in this complex is usually placed in a case that is a steel box with a coating that provides electrical strength and corrosion protection. Nowadays, electrically-safe flexible cable jumpers between batteries under a bolt are used almost everywhere in the battery, which is very convenient, reliable and maintainable when replacing individual batteries that have failed. The dimensions of the battery and its nominal voltage correspond to the number of 2-volt lead-acid batteries for batteries acid traction or the number of alkaline batteries $(1.3 \mathrm{~V})$ for traction nickel-iron batteries.

As for the chargers, now the industry produces devices with an automated charge mode. As a traction battery used both spreading and tubular. The tubular batteries use positive tubular electrodes and lattice-type negative electrode electrodes. And in spreading batteries both types of electrodes are spreading. Cyclic life of tubular batteries is quite large and amounts to 1000-1500 cycles. However, these batteries have lower starting (starter) electrical characteristics.

To improve the energy efficiency of battery charging complexes, it is advisable to use batteries with paste electrodes of appropriate thickness. Such batteries made with double separation (microporous plastic and glass fiber) and elastic compression of the electrodes will be more stable during cyclic operation. Batteries with spreading electrodes have a lower internal resistance and a higher utilization rate of the active mass, which provides better performance under jog and impulse loads and with short discharge modes, as well as increases the specific energy and battery power.

As the analysis of the available data shows, the use of traditional devices to charge mine batteries requires an increase in the efficiency of the charging process; in addition, the main parameters of the lead-acid traction battery have not been fully optimized. Remains important issues of saving materials in the manufacture of batteries, consumed electricity, reducing the cost of the process of transporting goods in the mines. Improving the efficiency of charging processes can be achieved by optimizing the charging mode, increasing the useful energy by increasing the energy density $(\mathrm{W} \cdot \mathrm{h} / \mathrm{kg})$ and the allowable current density through the electrode $[7,8]$.

The main task arising in the design of batteries, is to determine the parameters of the battery design, in which it will correspond to the required electrical characteristics. Lowered electrical characteristics of batteries may not satisfy the consumer, and overestimated - suggest an overrun of raw materials, components and energy. Therefore, when designing batteries, it is necessary to calculate the parameters of their design as accurately as possible.

However, at present there is no strict methodology for calculating the parameters of a lead battery. This is due to a large number of factors affecting the calculated values, and insufficient knowledge of their role in the battery. But the main difficulty stems from the fact that the processes occurring in the battery are too complex for accurate quantitative analysis. Usually, when calculating lead-acid batteries for various purposes, it is necessary to proceed from the experimental data obtained under various particular conditions. The main purpose of the calculation is to determine the most optimal battery design parameters with given electrical characteristics.

As a result of the research, a specific method has been developed, which allows to calculate all the basic design parameters of a lead-acid battery with specified electrical characteristics and design features. In this case, the design parameters determined in accordance with the proposed methodology are optimized for the consumption of materials for the manufacture of the battery. The methodology is based on the general concepts of the 
design and the basic principles of operation of lead-acid batteries, as well as the concept of nominal starter optimization described below and some idealized assumptions.

The initial electrical data of the battery, the properties of the materials used and some design requirements are used as initial data: nominal capacity $Q_{\mathrm{N}}$, electromotive force $\varepsilon$, starter current $I_{\mathrm{s}}$, specific capacities $q_{ \pm}$and active mass densities $\rho_{ \pm}$, starter current density on the surface of the plates $j_{\mathrm{st}}$, minimum electrode thickness $d^{ \pm}{ }_{\text {min }}$ and separator thickness $d_{\text {s }}$, coefficients the capacity of the current leads $\chi_{ \pm}$and the proportion of the surface of the electrodes $\gamma$, the shape parameters of the electrode unit $\left(d_{\mathrm{eu}}, \alpha, \beta\right)$, the electrolyte concentration at the beginning and at the end of discharge $g$ and $\mathrm{g}^{\prime}$.

As a result of appropriate calculations, it is possible to accurately determine the main parameters of the battery design: the number of active masses $m_{ \pm}$, the size and number of electrode plates $\left(d_{ \pm}, w, h\right.$ and $\left.n_{ \pm}\right)$, the number of battery cells $N$, the amount of electrolyte in a charged and discharged battery, $V_{\mathrm{el}}$ and $V_{\mathrm{el}}^{\prime}$.

Nominal starter battery design optimization is to minimize the consumption of materials for the manufacture of the battery, providing the required values of nominal capacity and "starter" current. Under the starter current hereinafter refers to the peak load current. The calculation of the basic parameters of the design in accordance with the proposed concept of nominal starter optimization is carried out in four stages:

1. Determination of the main parameters of the design, providing the required nominal capacity, based on the capacitive balance of active masses (nominal optimization). Capacitive balance condition: $Q^{+}{ }_{\mathrm{n}}=Q^{-}{ }_{\mathrm{n}}=Q_{\mathrm{N}}$.

2. Increasing the total active surface area of the electrode plates to provide the required starter current (if required). Baseline: $I_{\mathrm{st}}=I_{\mathrm{s}}$.

3. Reduction of the excess amount of active masses arising from the growth of the total electrode surface, and the corresponding minimization of the thickness of the electrodes. The minimization condition: $\Delta m_{+}+\Delta m_{-} \rightarrow \min \left(\Delta m_{ \pm}-\right.$excess active mass).

4. Determination of the amount of electrolyte corresponding to the found amount of active masses and concentration limits. The capacity used $Q_{\mathrm{N}}$ in the calculations is defined as $Q_{\mathrm{N}}=\min \left(Q_{\mathrm{n}}^{+}, Q^{-}{ }_{\mathrm{n}}\right)$.

There are three possible options for applying the proposed concept of nominal starter optimization for calculating the main parameters of the battery design:

1. The starter current of the battery after the stage of nominal optimization (1st stage of calculation) exceeds the required value. In this case, the 2 nd and 3rd stages are skipped. Features: rated capacity - required, starter current - more than required, design optimization - rated.

2. The required starter current is provided at the 2 nd stage of calculation. After reducing the excess amount of active masses (3rd stage), the nominal capacity of the battery again takes the desired value. Features: rated capacity - required, starter current - required, design optimization - mixed.

3. The nominal capacity of the battery after the first three stages of calculation exceeds the required value. In this case, starter optimization is provided at the 3rd stage. Features: rated capacity - more than the required, starter current - required, design optimization - starter.

\section{Results and discussion}

This technique was tested on rechargeable batteries with expanded current leads. Accurate calculation in accordance with the developed method allows minimizing the consumption of materials for the manufacture of a battery that meets the specified electrical and structural requirements.

For laboratory research of the charging process of mine electric locomotive batteries, 
specially designed single-type charging devices were used, which differ only in the power of the 3-phase power transformer and the rectifier unit. For example, a 3-phase dry transformer TS-14/0.66-CD with a capacity of $14 \mathrm{kV} \cdot$ A for a nominal voltage of $50 \mathrm{~Hz}$, $660-380 \mathrm{~V}$ at the input and $107 \mathrm{~V}$ at the output. The connection diagram of the transformer windings - III/ $\Delta$. Transformer cooling - natural, air with degree of protection IP00 according to GOST 14254.

The most suitable 3-phase bridge circuit proposed by A.N. Larionov (1923) and has found wide application. The method of cooling the charger is not forced by means of fans, but more secure and absolutely reliable - natural - by the thermal conductivity of the metal parts of the cabinet, the thermal radiation of the outer shell of the structure, and the convection of the surrounding air. The circuit diagram of the device for charging the battery, as well as the wiring diagram, was developed and tested.

The operation of the assembled system was tested to remove and test the electrical characteristics of a lead-acid battery from a 3-phase network using a remote control panel containing a magnetic starter and a single-phase $220 \mathrm{~V} / 36 \mathrm{~V}$ transformer.

When testing the system as a load (mine battery), an equivalent battery with a capacity of $Q_{\text {eq }}=Q_{5} / k$ was also used. In reality, an electric battery with a different degree of charge is placed on charge.

Charging processes were carried out in both manual and automatic modes in order to clarify the installation data. Based on the needs of practice, the charging complex called "Charger - Charging Battery" was worked out for no more than 10 hours and so that the system worked satisfactorily, not only for output voltages of $150 \mathrm{~V}$ and maximum current of $100 \mathrm{~A}$ for a capacity of $490 \mathrm{~A} \cdot \mathrm{h}$, but also $170 \mathrm{~V}-115 \mathrm{~A}, 210 \mathrm{~V}-115 \mathrm{~A}, 170 \mathrm{~V}-130 \mathrm{~A}$, $210 \mathrm{~V}-130 \mathrm{~A}$ for respectively capacities of $560 \mathrm{~A} \cdot \mathrm{h}$ and $640 \mathrm{~A} \cdot \mathrm{h}$. Work was conducted on equivalents of capacitive load. Rational parameters were calculated for the automatic charge mode. Figure 1 shows charge in optimal battery mode.

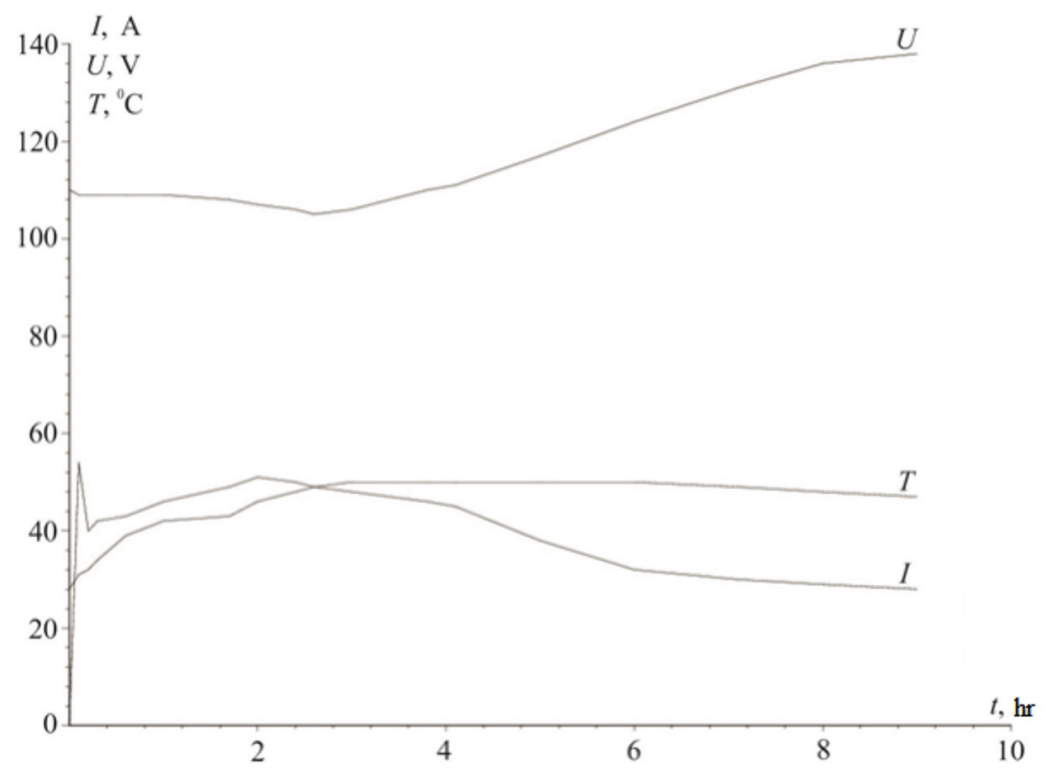

Fig. 1. Graph of charge is in the optimal mode.

The rational parameters include the charging current $I_{\mathrm{c}}$, the charging voltage $U_{\mathrm{c}}$ and the process temperature $T$, which must be provided for the full charge of the battery with varying degrees of discharge, with the maintenance of these parameters in automatic mode. 
The required charging modes are guaranteed by the design features of the charger and the manufacturing technology of sealed adsorbed glassmat (AGM) valve-regulated leadacid battery (VRLA) with immobilized electrolyte and gas recombination using an oxygen cycle.

Charging complexes and batteries for them are designed to work in harsh conditions, in an atmosphere of high humidity, gas pollution, high temperatures, constant charge discharges (at least daily). Therefore, in connection with the above requirements for construction and materials, real ways of their implementation were investigated and found.

As a result of the implementation of additional requirements of the battery and the chargers for them were on the performance of RP-devices. This provides a basis for developing CD-RP-type devices to be classified according to regulatory documentation as RP"e"(p)Is APS - mine explosion-proof electrical equipment of increased reliability against explosion (RP) with protection of the form "e" (p) (according to GOST 22782.7-81) and intrinsically safe electrical circuit (IC), as well as automatic protective shutdown (APS according to GOST 22782.5-78).

This level of protection is provided by:

a) creating an intrinsically safe circuit;

b) ensure, according to GOST 14254, the degree of protection IP54 of the cabinet against external influences;

c) execution of a restrictive regulating resistor $R_{\text {res }}$ from nichrome wire Ni80Cr20 (6$8 \mathrm{~mm}$ in diameter) in the form of an unfolded large-sized structure placed in quartz sand (GOST 22782.2-77) and attached externally to the back wall of the cabinet;

d) effective heat removal was provided not by forced cooling with the help of fans, but by thermal conductivity of the metal parts of the cabinet, thermal radiation from the outer shell of the cabinet structure and convection of outside air;

e) use of washers, nuts, brass or bronze jumpers.

The design of the above restrictive regulating resistor with dimensions of $60 \times 600 \times 1200 \mathrm{~mm}$ allows for effective heat dissipation by natural thermal conductivity (including metal parts of the charging cabinet) and external air convection, without resorting to the services of fans and without creating an additional risk of sparking but, on the contrary, increasing in principle the reliability of devices at the expense of the greatest possible lack of functional-power electronics.

With a properly selected $R_{\text {res }}$, conditions are reached when changes in the current $I$ during the cell charging process are such that the temperature associated with these changes stabilizes at a certain level and does not exceed $57^{\circ} \mathrm{C}$. This is a sure sign that the system will not overheat, and the battery will charge in an optimally short period of time with minimal energy consumption.

During the charging process, the latter is characterized by three stages, correlated in duration as 1:2:6. Obviously, the duration of the stages is determined by the charging current, which in turn depends on the battery capacity. For example, for a "soft" charge, when time is not limited, the total time to full charge is 48 hours.

Tests and checks began on fully charged standard batteries. In the absence of standard batteries, tests and checks were carried out with equivalents - batteries of lower capacity $Q_{\text {eq }}<Q_{5}$, but also fully charged. In this case, an additional resistor with a resistance equal to

$$
R_{\mathrm{add}}=(k-1) R_{\mathrm{res}},
$$

where $k=Q_{5} / Q_{\text {eq }}$ - proportionality coefficient. The power of the resistor $R_{\text {add }}$ was not less than the resistor $R_{\text {res. }}$. The load resistor $R_{\text {res }}$ was calculated using the experimentally found formula 


$$
R_{\mathrm{res}}=11.52 \cdot n / Q_{5}, \mathrm{Ohm}
$$

where $n$ - number of batteries in the battery. In the process of operation of the device and the execution of the charge of this battery, the input phase voltages $U_{\mathrm{ph}}$ and currents $I_{\mathrm{ph}}$ were measured and the power consumption $P$ was calculated when the star winding of the power transformer was turned on by a star:

$$
P=3 \cdot I_{\mathrm{ph}} \cdot U_{\mathrm{ph}} \cdot 10^{-3}, \mathrm{~kW}
$$

The results for CD-RP-104/490 are shown in Table 1.

Table 1. Technical parameters of the experimental charger CD-RP-104/490.

\begin{tabular}{|c|c|c|c|c|c|c|}
\hline $\begin{array}{c}\text { Type } \\
\text { (designation) of } \\
\text { device }\end{array}$ & \multicolumn{2}{|c|}{ Voltage $U, \mathrm{~V}$} & \multicolumn{2}{|c|}{$\begin{array}{c}\text { Current max, } \\
I_{\max }, \mathrm{A}\end{array}$} & $\begin{array}{c}\text { Overall dimensions, } \\
\text { length } \times \text { width } \times \\
\text { height, mm }\end{array}$ & $\begin{array}{c}\text { Power consumption } \\
P, \mathrm{~kW}\end{array}$ \\
\cline { 2 - 5 } & standard & fact & standard & fact & & \\
\hline CD-RP -104/490 & 150 & 147 & 100 & 95 & $950 \times 800 \times 1950$ & $\leq 14$ \\
\hline
\end{tabular}

The voltages and charge currents of $U_{\mathrm{c}}$ and $I_{\mathrm{c}}$ were tested for batteries with different degrees of discharge. The experimental device of the type CD-RP-104/490 was used to test its reliability and temperature during the run, that is, for a long period (about 3 days) of its continuous operation. Charges were conducted both on a standard battery as a load, and on the equivalent of an ohmic load in order to determine the limiting values of the load currents and temperatures. The measurements showed that the temperature did not exceed the permissible values. On the device type CD-RP-104/490, the operation of the protections was also checked.

A feature of the operation of the charging complex is that it operates in a cyclical mode of everyday charge-discharge in difficult underground conditions, hazardous in dust and gas, which requires special attention to the charging cycle mode both from the point of view of providing fire and explosion safety and long life resource.

A new electrode plate for a battery of an electric locomotive battery is fundamentally different from the existing ones and traditionally used in that it is a series connection of two grids through an intermediate collector obtained by the foundry method, which leads to a more uniform current load on the entire grid area, thus ensuring its more efficient and many years of work. In addition, in this case, the ohmic electrical resistance decreases.

Experimental studies have shown that for the first time double separation and compression of a block of pasted plates in a battery when using a separator of a new resiliently compressed glass fiber material (AGM) with high porosity and electrolyte adsorption, improve the stability during cycling, that is, increase the reliability and service life of the battery .An experimental study of the proposed battery charging complexes confirms the possibility and feasibility of introducing lead-acid batteries for mine electric locomotives in combination with appropriate charging devices. The obtained data showed that the prospect of transition to more economical accumulators with pasted plates of the "expanded tube" type instead of expensive tubular (armored) electrodes with pressed-in paste opens. For the first time, gas emission results were obtained depending on the operating modes of the VRLA recombination batteries. For these systems, air exchange rates in the working room have been calculated and tested.

According to the results of experimental studies of cyclic regimes, recommendations were developed for ensuring fire and explosion safety.

When constructing model chargers, the level of the switchgear was achieved - increased resistance to an explosion with protection of the form "e" from external influences, an intrinsically safe circuit and automatic shutdown. 
It should be noted that the modern mine complex in the form of a set of "Charger Battery" can be offered on the market as high scientific and technical products with the ability to operate with a high level of safety (as required by GOST 12.11.2-86) batteries and chargers to them. Proper optimal combination of "electric - high-tech battery - charger" - is a direct way to reduce the cost of products and at the same time to ensure reliability, durability and smooth operation.

\section{Conclusions}

1. The electrical properties of a chemical current source with a newly created and manufactured electrode plate, fundamentally different from those used in that the current lead of a new plate (electrode) is a series-parallel connection of two grids through a current collector, resulting in a more uniform current load of the electrode as a whole, thus ensuring more efficient and long-term operation.

2. A new design has been proposed and tested, as well as the manufacturing technology of a sealed, valve-regulated AGM-VRLA type battery with immobilized electrolyte and gas recombination using an oxygen cycle. For the first time, double separation and compression of accumulator battery plates were used by using as a separator elastically compressible (1.5-2.5 times) glass mat (AGM) with high porosity and electrolyte adsorption (90-92\%). It has been found that batteries of this kind have increased stability during cycling, i.e. more durable.

3. For the first time, the intensity of gas evolution for various operating modes of a sealed battery of recombination type with a valve-regulated system (VRLA) has been determined. Calculated air exchange rate in the working room, necessary for the safe charge of these batteries.

4. The features of the work of AGM-VRLA batteries in the mode of everyday "chargedischarge" have been studied and measures have been developed to ensure fire and explosion safety when operating lead-acid traction batteries in a coal mine.

5. For the first time, an experimental device of the type CD-RP-104/300-490 was developed, manufactured in an explosion-proof design and investigated using the key role of a restrictive control resistor as a mandatory functional element for charging a mine electric locomotive battery.

6 . The accelerated process of fully charging the mine electric locomotive battery as part of the CD-RP-104/300-490 and 52 BAT -300 (battery acid traction) complex was carried out automatically.

The results obtained determine the technical and technological conditions for the creation of a modern charging complex "Charger device - Battery" for a mine locomotive.

\section{References}

1. Kuznetsov, O.O., Kopig, V.Yu., Netessa, V.Ya. (2000). Self-discharge of the CDU for the danish spectroscopic spectroscopy, Fiziko-himichna mehanika materialiv, 2, 1, 592-595

2. Zimin, O., Pryvalov, V., Kalinovskyi Ye., Krys, V. (2000). Status and prospects of development of lead batteries of new generation in Ukraine, Visnik lvivskogo universitetu, 42 (1), 131-134

3. Kalinovskyi, Ye.A., Zimin, O.P., Pryvalov, V.N., Krys, V.Ya. (2006). Study of selfdischarge of lead-acid batteries, Voprosyi himii i himicheskoy tehnologii, 6, 163-167

4. Zimin, O.P, Pryvalov, V.M., Dzakovic, D.O., Kalinovskyi, Ye. A. (2007). Sposib viznachennya velichini samorozryadu svintsevo-kislotnoyi akumulyatornoyi batareyi. Patent No 79203, Ukraine 
5. Bagotsky, V.S., Skundin, A.M. (1981). Himicheskie istochniki toka. Moskva: Energoizdat

6. Kalinovskyi, Ye.A., Zimin, O.P., Krys, V.Ya., Pryvalov, V.N. (2006). Study on the possibility of creating low-maintenance sealed batteries, Voprosyi himii $i$ himicheskoy tehnologii, 5, 174-178

7. Kamenev, Yu.B., Kiseleva, A.V., Ostapenko, E.I., Skatchkov, Yu.V. (2001). Alloys for positive current leads of low-consumption lead-acid batteries, Elektrohimenergetika ,1, $3,17-20$

8. Polishchuk, Yu.V., Kolesnikova, N.A., Krys, V.Ya. (2004). Modified electrode materials for acid batteries of a new generation, Voprosyi himii $i$ himicheskoy tehnologii, 1, 163-166 